\title{
Increase in reflex vasoconstriction with indomethacin in patients with orthostatic hypotension and central nervous system involvement
}

\author{
TSUTOMU IMAIZUMI, AKIRA TAKESHITA, TOSHIAKI ASHIHARA, \\ MOTOOMI NAKAMURA, SADATOSHI TSUJI, * HIROSHI SHIBAZAKI^ \\ From the Research Institute of Angiocardiology and Cardiovascular Clinic, and the ${ }^{\star D e p a r t m e n t ~ o f ~ N e u r o l o g y, ~}$ \\ Neurological Institute, Faculty of Medicine, Kyushu University, Fukuoka, fapan
}

SUMMARY Since indomethacin may be effective in the treatment of orthostatic hypotension, the ability of this drug to increase reflex vasoconstriction was studied in six patients with orthostatic hypotension and in five normal subjects. Reflex forearm vasoconstriction during lower body negative pressure at $20-40 \mathrm{~mm} \mathrm{Hg}$ was measured before and after indomethacin $50 \mathrm{mg}$ by mouth. In patients with orthostatic hypotension and central nervous system involvement indomethacin increased recumbent blood pressure, resting forearm vascular resistance, and reflex forearm vasoconstriction during lower body negative pressure. The fall in blood pressure with lower body negative pressure was not significantly inhibited by indomethacin, but mean blood pressure during lower body negative pressure was higher after than before indomethacin. Indomethacin did not alter these responses in normal subjects. The increase in reflex vasoconstriction with indomethacin may contribute to its therapeutic effects in the treatment of orthostatic hypotension.

Orthostatic hypotension in patients with the ShyDrager syndrome or idiopathic Parkinsonism is caused by absent or depressed reflex vasoconstriction in response to standing. ${ }^{2}$ Several studies have suggested that indomethacin may be effective in the treatment of orthostatic symptoms in these patients. ${ }^{34}$ Indomethacin increases recumbent blood pressure and resting forearin vascular resistance and reduces the orthostatic fall in blood pressure. ${ }^{34}$ It is not, however, known whether indomethacin increases reflex vasoconstriction in response to standing in these patients.

The beneficial effect of indomethacin may result from inhibition of the vasodilator effect of prostaglandins. ${ }^{34}$ Prostaglandins not only act directly on resistance vessels but also indirectly by reducing the release of noradrenaline from the nerve endings or by decreasing vascular response to vasoconstrictor stimuli. ${ }^{5-7}$ Thus indomethacin may increase reflex

Requests for reprints to Dr Akira Takeshita, Research Institute of Angiocardiology and Cardiovascular Clinic, Faculty of Medicine, Kyushu University, 3-1-1 Maidashi, Higashi-ku, Fukuoka 812, Japan.

Accepted for publication 10 May 1984 vasoconstriction by blocking the inhibitory influence of prostaglandins on the release of noradrenaline or on vascular responses to noradrenaline.

In this study we examined whether indomethacin increased reflex forearm vasoconstriction in response to lower body negative pressure in patients with orthostatic hypotension and central nervous system involvement and compared the results with those in normal subjects of similar age. Lower body negative pressure decreases venous return to the cardiopulmonary region and triggers reflex vasoconstriction. ${ }^{8}$

\section{Patients and methods}

\section{STUDY POPULATION}

Six patients (age range 55-70 (mean 61 (SD2)) years) with orthostatic hypotension and central nervous system involvement were studied; five (cases. 1-5) had Shy-Drager syndrome and one (case 6) idiopathic Parkinsonism with orthostatic hypotension. The central nervous system signs in these patients included muscle rigidity (six), ataxia (three), hyper-reflexia (five), Babinski's sign (four), cranial nerve defects (four), muscle atrophy (three), and tremor (five). In addition, urinary incontinence or constipation was 
present in five patients. All patients had orthostatic hypotension (a mean fall in blood pressure on standing of 26 (SD3) $\mathrm{mm} \mathrm{Hg}$ ). A possible diagnosis of diabetes mellitus, amyloidosis, Addison's disease, porphyria, or heavy metal toxicity was eliminated. We also studied five normal subjects (age range 42-65 (mean 56 (SD5)) years). All drugs were withdrawn in patients with orthostatic hypotension at least a week before the study.

\section{MEASUREMENTS OF REFLEX FOREARM VASOCONSTRICTION}

Measurements were recorded with subjects in the supine position. The lower half of the subject's body below the iliac crest was enclosed in a sealed box connected to a vacuum. The negative pressure in the box produced by the vacuum reduced venous return and stimulated reflex vasoconstriction in the forearm. The level of negative pressure was varied by adjusting an air valve. Forearm blood flow was measured with a mercury in silastic strain gauge plethysmograph with a venous occlusion technique. ${ }^{9}$ The strain gauge was placed approximately $5 \mathrm{~cm}$ below the antecubital crease. The pressure in the venous occlusion or congesting cuff was $40 \mathrm{~mm} \mathrm{Hg}$. Circulation to the hand was stopped by inflating a cuff around the wrist during determination of the forearm blood flow. Blood pressure was measured by a sphygmomanometer in the opposite arm, heart rate calculated from an electrocardiogram, and vascular resistance calculated by dividing the mean blood pressure $(\mathrm{mm} \mathrm{Hg}$ ) by the forearm blood flow $(\mathrm{ml} / \mathrm{min}$ per $100 \mathrm{ml}$ of forearm volume) and expressed in units. The mean blood pressure was calculated by adding one third of the pulse pressure to the diastolic pressure. In three patients with orthostatic hypotension and in four normal subjects the right subclavian vein was cannulated and the central venous pressure recorded.

\section{PROTOCOL}

After the plethysmograph and venous catheter had been positioned and the box sealed, at least 15 minutes were allowed for the subjects to become accustomed to the study conditions. Blood pressure, heart rate, central venous pressure, and forearm blood flow were then measured at rest and during lower body negative pressure. In normal subjects, negative pressure was applied at $\mathbf{4 0} \mathrm{mm} \mathrm{Hg}$. In patients with orthostatic hypotension negative pressure was applied at either $20 \mathrm{~mm} \mathrm{Hg}, 30 \mathrm{~mm} \mathrm{Hg}$, or $40 \mathrm{~mm} \mathrm{Hg}$ because in some patients a pressure of $40 \mathrm{~mm} \mathrm{Hg}$ produced severe hypotension and fainting before indomethacin was given.

Indomethacin $50 \mathrm{mg}$ was given orally and measurements were repeated one hour later at rest and during lower body negative pressure. The negative pressure applied after indomethacin was the same as that before indomethacin in each subject.

\section{STATISTICAL ANALYSIS}

Unpaired and paired Student's $t$ tests were used for statistical analysis, and $p \leqslant 0.05$ was considered significant. Data are expressed as mean (SEM).

\section{Results}

\section{RESTING HAEMODYNAMICS}

Before indomethacin, mean blood pressure, heart rate, central venous pressure, forearm blood flow, and forearm vascular resistance at rest in the recumbent position were similar in normal subjects and in patients with orthostatic hypotension (Table 1). Indomethacin increased mean blood pressure and decreased heart rate in patients with orthostatic hypotension but not in normal subjects. It did not change forearm blood flow in either group, and increased forearm vascular resistance in patients with orthostatic hypotension but not in normal subjects.

RESPONSE TO LOWER BODY NEGATIVE PRESSURE

Before indomethacin-In normal subjects lower body negative pressure at $40 \mathrm{~mm} \mathrm{Hg}$ decreased central venous pressure, did not change mean blood pressure, but increased heart rate (Table 2). It decreased forearm blood flow and increased forearm vascular resistance. In contrast, in patients with orthostatic

Table 1 Resting haemodynamic measurements (mean (SEM) values) in six patients with orthostatic hypotension (study group) and five normal subjects (control group)

\begin{tabular}{|c|c|c|c|c|}
\hline & \multicolumn{2}{|c|}{ Before indomethacin } & \multicolumn{2}{|c|}{ After indomethacin } \\
\hline & Study group & Control group & Study group & Control group \\
\hline $\begin{array}{l}\text { Heart rate (beats/min) } \\
\text { Mean blood pressure (mm } \mathrm{Hg}) \\
\text { Central venous pressure }(\mathrm{mm} \mathrm{Hg}) \\
\text { Forearm blood flow (ml/min/100 mH }) \\
\text { Forearm vascular resistance (units) }\end{array}$ & $\begin{array}{l}62(3) \\
103(4) \\
4 \cdot 0(0 \cdot 3) \\
4 \cdot 4(0 \cdot 4) \\
24(3)\end{array}$ & $\begin{array}{l}56(7) \\
87(4) \\
4 \cdot 8(0 \cdot 6) \\
4 \cdot 3(0 \cdot 7) \\
23(4)\end{array}$ & $\begin{array}{l}55(2)^{\star} \\
122(4)^{\star} \\
5 \cdot 2(0 \cdot 3) \\
4 \cdot 4(0 \cdot 4) \\
28(3)^{\star \star}\end{array}$ & $\begin{array}{l}53(7) \\
93(7) \\
5 \cdot 1(0 \cdot 4) \\
4 \cdot 1(0 \cdot 5) \\
24(3)\end{array}$ \\
\hline
\end{tabular}

${ }^{\star} \mathrm{p}<0.01$ before $v$ s after indomethacin; ${ }^{\star \star} \mathrm{p}<0.05$ before $v s$ after indomethacin.

tForearm volume. 
able 2 Change in haemodynamic measurements with lower body negative pressure (LBNP) in six patients with orthostatic hypotension ases 1-6) and five normal subjects (cases 7-11)

\begin{tabular}{|c|c|c|c|c|c|c|c|c|c|c|c|c|c|}
\hline & \multicolumn{13}{|c|}{ Case Nos } \\
\hline & 1 & 2 & 3 & 4 & 5 & 6 & Mean (SEM) & 7 & 8 & 9 & 10 & 11 & $\operatorname{Mean}(S E M)$ \\
\hline $\begin{array}{l}\text { ower body negative pressure } \\
(\mathrm{mm} \mathrm{Hg})\end{array}$ & 20 & 20 & 20 & 30 & 40 & 40 & & 40 & 40 & 40 & 40 & 40 & \\
\hline \multicolumn{14}{|c|}{ Before indomethacin } \\
\hline $\begin{array}{l}\text { lean blood pressure }(\mathrm{mm} \mathrm{Hg}) \\
\text { leart rate (beats/min) } \\
\text { orearm blood flow } \\
\text { (ml/min } 100 \mathrm{mH})\end{array}$ & $\begin{array}{l}-17 \\
-1 \cdot 0\end{array}$ & $\begin{array}{l}-10 \\
-12 \\
-1 \cdot 5\end{array}$ & $\begin{array}{l}-15 \\
10 \\
-2 \cdot 1\end{array}$ & $\begin{array}{l}-14 \\
-2 \\
-1 \cdot 3\end{array}$ & $\begin{array}{l}-27 \\
10 \\
-0.8\end{array}$ & $\begin{array}{l}-18 \\
-2 \\
-1 \cdot 0\end{array}$ & $\begin{array}{l}-16 \cdot 8(2 \cdot 3)^{\star} \\
1 \cdot 3(3 \cdot 5) \\
-1 \cdot 3(0 \cdot 2)^{\star}\end{array}$ & $\begin{array}{l}-10 \\
13 \\
-2 \cdot 5\end{array}$ & $\begin{array}{l}-2 \\
-1 \cdot 5\end{array}$ & $\begin{array}{l}-8 \\
-1 \cdot 8\end{array}$ & $\begin{array}{l}0 \\
9 \\
-1 \cdot 2\end{array}$ & $\begin{array}{l}2 \\
14 \\
-1 \cdot 5\end{array}$ & $\begin{array}{l}-3 \cdot 6(2 \cdot 3) \\
8 \cdot 8(2 \cdot 2)^{\star \star} \\
-1 \cdot 7(0 \cdot 2)^{\star}\end{array}$ \\
\hline $\begin{array}{l}\text { orearm vascular resistance (units) } \\
\text { entral venous pressure (mm } \mathbf{H g} \text { ) }\end{array}$ & $\begin{array}{l}2 \cdot 1 \\
-2 \cdot 5\end{array}$ & $\begin{array}{l}18 \cdot 3 \\
-3 \cdot 5\end{array}$ & $\begin{array}{l}7 \cdot 0 \\
-3 \cdot 2\end{array}$ & $5 \cdot 1$ & $\begin{array}{l}-0 \cdot 1 \\
-\end{array}$ & 0.8 & $\begin{array}{l}5.5(2 \cdot 8) \\
-3 \cdot 1(0.3)^{\star}\end{array}$ & $\begin{array}{l}22 \cdot 0 \\
-3 \cdot 4\end{array}$ & $\begin{array}{l}18 \cdot 8 \\
-4 \cdot 2\end{array}$ & $\begin{array}{l}10 \cdot 0 \\
-3 \cdot 8\end{array}$ & $\begin{array}{l}14 \cdot 3 \\
-3 \cdot 4\end{array}$ & $27 \cdot 0$ & $\begin{array}{l}18.4(2.9)^{\star} \\
-3.7(0.2)^{\star}\end{array}$ \\
\hline \multicolumn{14}{|c|}{ After indomethacin } \\
\hline $\begin{array}{l}\text { lean blood pressure }(\mathrm{mm} \mathrm{Hg}) \\
\text { leart rate (beats/min) } \\
\text { orearm blood flow } \\
(\mathrm{ml} / \mathrm{min} / 100 \mathrm{ml}\end{array}$ & $\begin{array}{l}-18 \\
-2 \cdot 3\end{array}$ & $\begin{array}{l}-15 \\
-2 \cdot 7\end{array}$ & $\begin{array}{l}-6 \\
8 \\
-2 \cdot 4\end{array}$ & $\begin{array}{l}-19 \\
2 \\
-3.4\end{array}$ & $\begin{array}{l}-4 \\
6 \\
-1.4\end{array}$ & $\begin{array}{l}-14 \\
-2 \cdot 0\end{array}$ & $\begin{array}{l}-11(2 \cdot 2)^{\star} \\
5 \cdot 2(1 \cdot 2)^{\star} \\
-2.4(0.3)^{\star}\end{array}$ & $\begin{array}{l}-2 \\
-1 \cdot 4\end{array}$ & $\begin{array}{l}-9 \\
-1.6\end{array}$ & $\begin{array}{l}-8 \\
-2 \cdot 0\end{array}$ & $\begin{array}{l}0 \\
9 \\
-2 \cdot 3\end{array}$ & $\begin{array}{l}-2 \\
10 \\
-2.8\end{array}$ & $\begin{array}{l}-4.2(1.8) \\
7(1.3)^{\star} \\
-2.0(0.3)^{\star}\end{array}$ \\
\hline $\begin{array}{l}\text { orearm vascular resistance (units) } \\
\text { entral venous pressure (mm } \mathbf{~ H g} \text { ) }\end{array}$ & $\begin{array}{l}14.7 \\
-2.7\end{array}$ & $\begin{array}{l}7 \cdot 8 \\
-4 \cdot 3\end{array}$ & $\begin{array}{l}11 \cdot 7 \\
-4 \cdot 2\end{array}$ & 29.3 & $31 \cdot 3$ & $11 \cdot 3$ & $\begin{array}{l}17.7(4 \cdot 1)^{\star} \\
-3.7(0.5)^{\star}\end{array}$ & $\begin{array}{l}30.0 \\
-3.4\end{array}$ & $\begin{array}{l}14 \cdot 2 \\
-4 \cdot 6\end{array}$ & $\begin{array}{l}30.8 \\
-4.2\end{array}$ & $\begin{array}{l}10.1 \\
-3.5\end{array}$ & $12 \cdot 8$ & $\begin{array}{l}19.6(4.5)^{\star} \\
-3.9(0.3)^{\star}\end{array}$ \\
\hline
\end{tabular}

$\mathrm{p}<0.001$, resting $v$ during $\mathrm{LBNP} ;{ }^{\star \star} \mathrm{p}<0.05$ resting vs during $\mathrm{LBNP}$.

Forearm volume.

hypotension negative pressure at 20,30 , or $40 \mathrm{~mm} \mathrm{Hg}$ decreased mean blood pressure but did not change heart rate or forearm vascular resistance. Forearm blood flow decreased during negative pressure, but the decrease was due to the decrease in blood pressure since forearm vascular resistance was unchanged. The falls in central venous pressure with negative pressure were similar in patients with orthostatic hypotension and in normal subjects.

After indomethacin-In normal subjects indomethacin did not alter the response of blood pressure, heart rate, and central venous pressure to negative pressure at $40 \mathrm{~mm} \mathrm{Hg}$ (Table 2). The decrease in forearm blood flow and the increase in forearm vascular resistance were also unchanged. In patients with orthostatic hypotension, however, indomethacin increased reflex forearm vasoconstriction. The decrease in mean blood pressure was less but not significantly after indomethacin. Heart rate increased after indomethacin. The decrease in central venous pressure was similar before and after indomethacin. Although the decrease in mean blood pressure was not significantly different before and after indomethacin mean blood pressure during negative pressure was higher $(p<0.05)$ after indomethacin $(105(4) \mathrm{mm} \mathrm{Hg})$ than before (86(4) $\mathrm{mm} \mathrm{Hg}$ ). Four patients who felt faint during negative pressure at $40 \mathrm{~mm} \mathrm{Hg}$ before indomethacin tolerated a pressure of $40 \mathrm{~mm} \mathrm{Hg}$ after indomethacin.

\section{Discussion}

The major finding of this study is that indomethacin increased reflex forearm vasoconstriction in response to lower body negative pressure in patients with orthostatic hypotension and central nervous system signs. Before indomethacin there was virtually no reflex forearm vasoconstriction with negative pressure in patients with orthostatic hypotension despite a pronounced fall in blood pressure, whereas after indomethacin negative pressure at the same level as before indomethacin produced significant reflex forearm vasoconstriction. In contrast, indomethacin did not alter reflex forearm vasoconstriction in normal subjects.

Reflex forearm vasoconstriction during lower body negative pressure is mediated by the decrease in tonic inhibitory influence of cardiopulmonary as well as arterial baroreceptors on the vasomotor centre. ${ }^{8}$ The possibility that the increase in forearm vasoconstriction with indomethacin in patients with orthostatic hypotension was related to non-specific mechanisms such as a greater stimulus to the baroreceptors or the difference in baseline forearm vascular resistance should be considered. Nevertheless, the decreases in central venous pressure as well as in mean blood pressure were not different before and after indomethacin. Vascular responses to vasoconstrictor stimuli are greater when the vessels are less constricted. ${ }^{10}$ Baseline vascular resistance was, however, higher after than before indomethacin. Thus the results cannot be explained by non-specific mechanisms but suggest that indomethacin increases reflex vasoconstriction in patients with orthostatic hypotension and central nervous system involvement but not in normal subjects. 
The increases in forearm vascular resistance with lower body negative pressure after indomethacin in patients with orthostatic hypotension were similar to those in normal subjects. Nevertheless, blood pressure fell in patients with orthostatic hypotension but not in normal subjects. Thus the reflex stimulus was greater in patients with orthostatic hypotension than in normal subjects. It appears, therefore, that indomethacin only partially improves reflex vasoconstriction in patients with orthostatic hypotension and central nervous system involvement.

Despite increased reflex forearm vasoconstriction by indomethacin the fall in mean blood pressure with lower body negative pressure was not significantly less after indomethacin in patients with orthostatic hypotension. The reason for this finding is not clear, but it might be related to the fact that reflex activation of sympathetic outflow during lower body negative pressure is not uniform. Reflex vasoconstriction with lower body negative pressure is greater in the forearm vessels than in the splanchnic vessels. ${ }^{11}$ It is possible that blood pressure fell during lower body negative pressure because of failure to increase splanchnic vascular resistance with this stimulation.

In addition to the increases in reflex vasoconstriction indomethacin increased resting blood pressure and forearm vascular resistance in patients with orthostatic hypotension and central nervous system involvement but not in normal subjects. These results are similar to those in previous reports by Kochar and Itskovitz ${ }^{3}$ and by Abate et al. ${ }^{4}$ Nevertheless, failure to improve orthostatic symptoms has also been reported. ${ }^{12} 13$ We do not understand the mechanisms by which indomethacin is beneficial in some but not in other patients with orthostatic hypotension nor those by which indomethacin increased reflex vasoconstriction in our patients. Previous studies suggest that in some patients with orthostatic hypotension and central nervous system involvement efferent sympathetic nerves are relatively intact and noradrenaline is not depleted in the nerve endings. ${ }^{214}$ In such patients, indomethacin may increase reflex vasoconstriction by blocking the inhibitory influence of prostaglandins on the release of noradrenaline or on the vascular response to noradrenaline. ${ }^{5-7}$ The various effects of indomethacin in patients with orthostatic hypotension may possibly be related to the difference in basic abnormality in the central and sympathetic nervous system.
In summary, the results of this study indicate that indomethacin increases reflex forearm vasoconstriction in response to lower body negative pressure in patients with orthostatic hypotension and central nervous system involvement. The increase in reflex vasoconstriction by indomethacin may contribute to its therapeutic effects in the treatment of orthostatic hypotension.

\section{References}

1 Bradbury S, Eggleston C. Postural hypotension: a report of three cases. Am Heart f 1926; 1: 73-86.

2 Ziegler MG, Lake CR, Kopin IJ. The sympatheticnervous-system defect in primary orthostatic hypotension. $N$ Engl F Med 1977; 296: 293-7.

3 Kochar MS, Itskovitz HD. Treatment of idiopathic orthostatic hypotension (Shy-Drager syndrome) with indomethacin. Lancet 1978; i: 1011-4.

4 Abate G, Polimeni RM, Cuccurullo F, Puddu P, Lenzi S. Effects of indomethacin on postural hypotension in Parkinsonism. Br Med F 1979; ii: 1466-8.

5 Malik KU, Ryan P, McGiff JC. Modification by prostaglandins $E_{1}$ and $E_{2}$, indomethacin, and arachidonic acid of the vasoconstrictor responses of the isolated perfused rabbit and rat mesenteric arteries to adrenergic stimuli. Circ Res 1976; 39: 163-8.

6 Brody M, Kadowitz PJ. Prostaglandins as modulators of the autonomic nervous system. Fed Proc 1974; 33: 4860.

7 Hedquiat $\mathrm{P}$. Actions of prostacyclin $\left(\mathrm{PGI}_{2}\right)$ on adrenergic neuroeffector transmission in the rabbit kidney. Prostaglandins 1979; 17: 249-58.

8 Mark AL, Kerber RE. Augmentation of cardiopulmonary baroreflex control of forearm vascular resistance in borderline hypertension. Hypertension 1982; 4: 39-46.

9 Whitney RJ. The measurement of volume changes in human limbs. I Physiol (Lond) 1953; 121: 1-27.

10 Myers HA, Honig CR. Influence of initial resistance on magnitude of response to vasomotor stimuli. Am $\mathcal{F}$ Physiol 1969; 216: 1429-36.

11 Streeten DHP, Kerr LP, Kerr CB, Price JC, Dalakos TG. Hyperbradykinism: a new orthostatic syndrome. Lancet 1972; ii: 1048-53.

12 Davies IB, Bannister R, Sever PS. Indomethacin treatment of postural hypotension in autonomic failure (Letter). $\mathrm{Br} \mathrm{Med} \mathcal{F}$ 1980; 280: 181.

13 Crook JE, Robertson D, Whorton AR. Prostaglandin suppression: inability to correct severe idiopathic orthostatic hypotension. South Med f 1981; 73: 318-20.

14 Kontos HA, Richardson DW, Norvell JE. Mechanisms of circulatory dysfunction in orthostatic hypotension. Trans Am Clin Climatol Assoc 1975; 87: 26-35. 